\title{
Elämää resurssimosaiikissa - Ilmastonmuutos parantaa koloradonkuoriaisen ilmastollisia eväitä mutta paikalliset erot ja pohjoinen elinpiiri tuovat haasteensa kotiutumiselle
}

\author{
Sini Ooperi ${ }^{1}$ ja Eduardo González ${ }^{2}$ \\ ${ }^{1}$ Maataloustieteiden laitos, PL 27, 00014 Helsingin yliopisto, sini.ooperi@helsinki.fi \\ ${ }^{2}$ Metsätieteiden laitos, PL 27,00014 Helsingin yliopisto, eduardo.gonzalezlatorre@helsinki.fi
}

\section{Tiivistelmä}

Kasvinviljelyn lisäksi ilmastonmuutos tuo lisää resursseja myös karanteenituhoojien, kuten koloradonkuoriaisen, kotiutumiselle. Uudet resurssit eivät kuitenkaan jakaudu tasaisesti joten kysymys kuuluu: Missä on parhaat oltavat koloradonkuoriaiselle v. 2012-2100? Vastauksilla voi olla merkitystä kuoriaisen pitkän aikavälin tarkkailun ja torjunnan suunnittelussa sekä suojavyöhykkeen sijaintiin ja maantieteelliseen laajuuteen liittyvässä päätöksenteossa. Tässä työssä olemme tarkastelleet kuoriaisen resursseja v. 1971-2000 ja eri ilmastonmuutosskenaarioissa, sillä missä resurssit ovat parhaimmat, siellä kotiutumisriskikin on suurin.

Resurssiennusteet perustuvat koloradonkuoriaisen lisääntymis-, levintä- ja talvehtimisvasteisiin, joiden pohjalta on mallinnettu joukko resurssi-indeksejä. Ennusteet on tehty ILMASOPU-tutkimuksissa käytetyille skenaarioille (A2 ja B1; 2025 $\pm 15,2055 \pm 15$ ja $2085 \pm 15)$, mutta resoluutio on tarkempi $(10 \mathrm{~km})$. Tähän on päästy luokittelemalla Ilmatieteen laitoksen $10 \mathrm{~km}$ hilaverkko merellisiin, järvisiin ja mantereisiin ruutuihin. Kullekin 3 luokalle on tehty regressiomallit, joiden avulla on saatu päivittäiset minimi- ja maksimilämpötilat. Kaikki resurssi-indeksit on laskettu sekä vertailuperiodille 1971-2000 että 6 skenaariolle.

Kesien osalta laskettiin lisääntymiseen käytössä oleva lämpösumma, siihen pohjautuva kasvuindeksi ja sukupolvien määrä. Lisäksi laskettiin aktiivista levintää kuvaava indeksi, joka perustuu lentoonlähtöpäivien määrään ja suotuisuuteen. Talvehtimisoloja varten luotiin joukko indeksejä, jotka kuvaavat diapaussin aikaisia sääoloja: 1) suojasääsumma ja -indeksi, 2) pakkasumma ja -indeksi, 3) talvehtisen alun, keskitalven ja talvehtimisen lopun kylmäshokki-indeksit ja 4) vuosien 1971-2000 suojasääkausien lukumäärään ja ankaruuteen perustuva indeksi. Kaikki tunnusluvut laskettiin omista aikaikkunoistaan, jotka määräytyvät kuoriaisen fenologian perusteella. Tästä syystä aktiivivaiheen ja diapaussin pituus ja ajoittuminen vaihtelevat eri skenaarioissa.

Tuloksista ilmenee mm. että kotiutumiselle mahdollinen alue, jossa kuoriainen voi tuottaa uuden sukupolven siirtyy maltillisemmassakin skenaariossa vuosisadan loppuun mennessä $\mathrm{n} .600 \mathrm{~km}$ pohjoisemmaksi $\left(74,85^{\circ} \mathrm{N}\right)$ kuin nykyilmaston mukainen raja $\left(1986 \mathrm{~A} 2 ; 68,75^{\circ} \mathrm{N}\right)$. Ravintoresursseistakaan ei liene pulaa, sillä kaupallisia perunapeltoja on vielä leveysasteella $76^{\circ} \mathrm{N}$, minkä lisäksi omatarveperunaa on hyvin yleisesti maatilojen ja mökkien yhteydessä. Mahdollisissa jatkotutkimuksissa olisi hyvä keskittyä siihen, miten kuoriaisen talvehtimiskuolleisuutta voitaisiin ennustaa nykyistä paremmin. Ennestään tiedetään, että mm. maalaji ja kylmäshokit vaikuttavat kuolleisuuteen (mm. Hiiesaar ym. 2006), mutta alustavien tulostemme mukaan erityisesti suojasääkausien ankaruuden mukaanotto parantaisi ennusteiden tarkkuutta entisestään. Olisi hyvä selvittää myös mitä resurssikartoitusten tulokset käytännössä tarkoittavat kuoriaisen torjunnassa ja siihen liittyvässä päätöksenteossa.

AVAINSANAT: koloradonkuoriainen, ilmastonmuutos, kotiutumisriski, talvehtiminen, tulokaslajit 


\section{Johdanto}

Koloradonkuoriaisia, jotka ovat maassamme karanteenituhoojia, on tullut useaan otteeseen Suomeen mm. vuosina 1998, 2002 ja 2004. Suurin näistä invaasioista oli vuonna 2002, jolloin löydettiin 324 saastuntaa. Kuoriaisia on löytynyt näiden vuosien jälkeen taannehtivasti vain muutamilta saastuntapaikoilta, jotka ovat olleet hyvin lähellä edellisiä saastuntoja. Tämän on arveltu viitaavan sihen, että kuoriaisen pystyy talvehtimaan Suomen nykyilmastossa ja että tästä johtuen se pystyy muodostamaan pysyvän kannan ellei saastuntoja saada hävitettyä. Viime kesänä löydettiin kaikkiaan 38 esiintymää, joista viimeiset havainnot vasta syyskuun puolivälissä (EVIRA 2011).

Tämän tutkimuksen tavoiteena oli selvittää, millaisia resurssimuutoksia muuttuva ilmasto tuo näille Suomeen kotiutumista yrittäville koloradonkuoriaisille tällä vuosisadalla. On oletettavaa, että kuoriaisen aktiivija lepovaiheen fenologia tulee muuttumaan huomattavasti vuosisadan loppua kohden mentäessä ja että käytössä olevat resurssit eivät tule jakautumaan tasaisesti ympäri Suomea. Kysymys kuuluukin: Missä on parhaat oltavat koloradonkuoriaiselle v. 2012-2100?

Vastauksilla voi olla merkitystä kuoriaisen lähiajan torjuntaa ja tarkkailua suunniteltaessa, mutta myös pitkän aikavälin strategisessa suunnittelutyössä mm. siinä, missä suojavyöhykkeen olisi hyvä sijaita ja kuinka laaja sen tulisi olla, vai tulisiko siitä jopa luopua ja jos niin missä vaiheessa. Tässä työssä olemme tarkastelleet kuoriaisen resursseja lähimenneisyydessä v.1971-2000 ja eri ilmastonmuutosskenaarioissa, sillä missä resurssit ovat parhaimmat, siellä kotiutumisriskikin on suurin.

\section{Aineisto ja menetelmät}

Tehdyt resurssiennusteet perustuvat koloradonkuoriaisen lisääntymis-, levintä- ja talvehtimisvasteisiin, joiden pohjalta on mallinnettu joukko resurssi-indeksejä (ks. Ooperi\&Jolma 2009). Ennusteet on tehty ILMASOPUtutkimuksista tutuille skenaarioille (A2 ja B1; 2025 $\pm 15,2055 \pm 15$ ja $2085 \pm 15$ ), ja verrattu ajanjaksoon 1971 2000 (ks. skenaariot Peltonen-Sainio ym 2009). Resoluutio on kuitenkin tarkempi, 10 km, kuin näissä skenaarioissa oleva $0,5^{\circ}(\mathrm{n} .50 \mathrm{~km})$. Luokittelimme Ilmatieteen laitoksen $10 \mathrm{~km}$ hilaverkon ruudut merellisiin, järvisiin ja mantereisiin luokkiin SPSS 15.0 luokittelupuu-algoritmilla, joka maksimoi luokkien sisäistä yhdenmukaisuutta (SPSS 2007). Tämän jälkeen kullekin 3 luokalle tehtiin lineaariset regressiomallit, joiden avulla laskimme päivittäiset minimi- ja maksimilämpötilat em. ennusteperiodeille kahdessa eri päästöskenaariossa (A2 ja B1).

Resurssi-indeksien laskemiseksi määritimme tarvittavat aikaikkunat, joista tunnusluvut laskettiin. Kaikki tunnusluvut ja niiden laskenta ohjelmoitiin perl-kielellä, kun taas aikaikkunoiden määrittelemiseksi tehdyt koodaukset tehtiin python-kielellä. Kesien osalta laskettiin lisääntymiseen käytössä oleva lämpösumma ja siihen pohjautuva kasvuindeksi sekä sukupolvien määrä. Lisäksi laskettiin aktiivista levintää kuvaava indeksi, joka perustuu lentoonlähtöpäivien määrään ja suotuisuuteen. Talvehtimisoloja varten luotiin joukko indeksejä, jotka kuvaavat diapaussin aikaisia sääoloja: 1) suojasääsumma ja -indeksi, 2) pakkasumma ja -indeksi, 3) talvehtisen alun, keskitalven ja talvehtimisen lopun kylmäshokki-indeksit ja 4) vuosien 1971-2000 suojasääkausien lukumäärään ja ankaruuteen perustuva indeksi. Kaikki tunnusluvut laskettiin siis omista aikaikkunoistaan, jotka määräytyvät kuoriaisen fenologian perusteella. Tästä syystä aktiivisen periodin ja diapaussin pituus ja ajoittuminen vaihtelevat karttaruuduittain skenaarioista toiseen. Kartoitimme kaikki resurssit sekä vertailuperiodille 1971-2000, 6 skenaariolle ja kullekin yksittäiselle vuodelle 1971-2000.

Lopuksi tulokset tuotiin ArcGIS 9 ArcMap 9.2 ohjelmaan karttatasoiksi sekä visualisointia että tulevia jatkoanalyysejä varten. On hyvä huomioida, että tehdyt ennusteet perustuvat keskiarvoaineistoihin, joten ne eivät ota huomioon vuosivaihtelua eivätkä sään ääri-ilmiöiden yleistymistä . Lasketut resurssi-indeksit ja tunnuslukut ovat siis 30-vuoden keskiarvoja, eivätkä pysty kuvaamaan luotettavasti tilanteita, jolloin jokin yht'äkkinen sääilmiö voi joko tuoda tai viedä resursseja nopeaan tahtiin. 


\section{Tulokset ja tulosten tarkastelu}

Vuosisadan loppua kohden mentäessä koloradonkuoriaisen aktiivivaihe muuttuu huomattavasti. Kun tähän asti olemme oppineet, että aktiivivaihe ajoittuu eteläisessä Suomessa noin juhannuksen tienoilta syyskuun alkuun, niin vuosisadan loppua kohden mentäessä se alkaa jo kesäkuun alusta ja kestää syyskuun loppupuolelle. Aktiivivaiheen kesto kasvaa Etelä-ja Keski-Suomessa, (leveysaste $<73,25^{\circ}$ ), parhaimmillaan n. 40 päivällä, siten että näistä n. 20 tulee alku- ja 20 loppupäähän, kun taas Pohjois-Suomessa, (leveysaste $\geq 73,25^{\circ}$ ), aktiivikausi loppuu päivänpituuden lyhenemisen ja sään viilentymisen vuoksi jo syyskuun 2.-6. päivä. Tällä alueella aktiivivaihe kasvaa nimenomaan alkupäästä, enimmillään n. 20 päivällä (Taulukko 1, Kuva 1).

Taulukko1. Koloradonkuoriaisen aktiivivaiheen pituus talvehtimisen lopusta seuraavan talvehtimisen alkuun.

\begin{tabular}{|l|c|c|c|c|}
\hline \multirow{2}{*}{ vrklskenaario } & \multicolumn{2}{|c|}{ Etelä-Suomi } & \multicolumn{2}{c|}{ Pohjois-Suomi } \\
\cline { 2 - 5 } & $1971-2000$ & $2085 \mathrm{~A} 2$ & $1971-2000$ & 2085A2 \\
\hline minimi & 57 & 79 & 21 & 63 \\
maksimi & 79 & 118 & 69 & 88 \\
keskiarvo & 70,5 & 96,5 & 55,8 & 78,3 \\
mediaani & 71 & 94 & 57 & 79 \\
hajonta & 4,559 & 9,694 & 7,450 & 4,971 \\
\hline
\end{tabular}

Pohjois-Suomen osalta kesien tarjoamat resurssit näyttävät lisääntyvän erityisesti alueella, joka sijoittuu Tornioja Kemijoen seudulle ja jatkuu Rovaniemelle päin rajautuen Pelloon, Tornioon ja Kemiin (Kuva1a ja 2). Tällä alueella voi skenaarion 2085 A2 mukaan esiintyä vielä 1 sukupolvi kesässä melkoisella varmuudella, kun taas pohjoisemmassa Suomessa kesät säilyvät sen verran viileinä, että vaikka laskennallisesti 1 sukupolvi voisi esiintyä, niin käytännössä tämä ei tule olemaan mahdollista joka vuosi vuosittaisen säävaihtelun vuoksi. EteläSuomessa esiintyy vaivatta 2 sukupolvea niin, että toisen sukupolven kuoriaisetkin ehtivät valmistua talvehtimiseen kaikessa rauhassa, toisin kuin pohjoiset kanssasisarensa (Kuva 2).

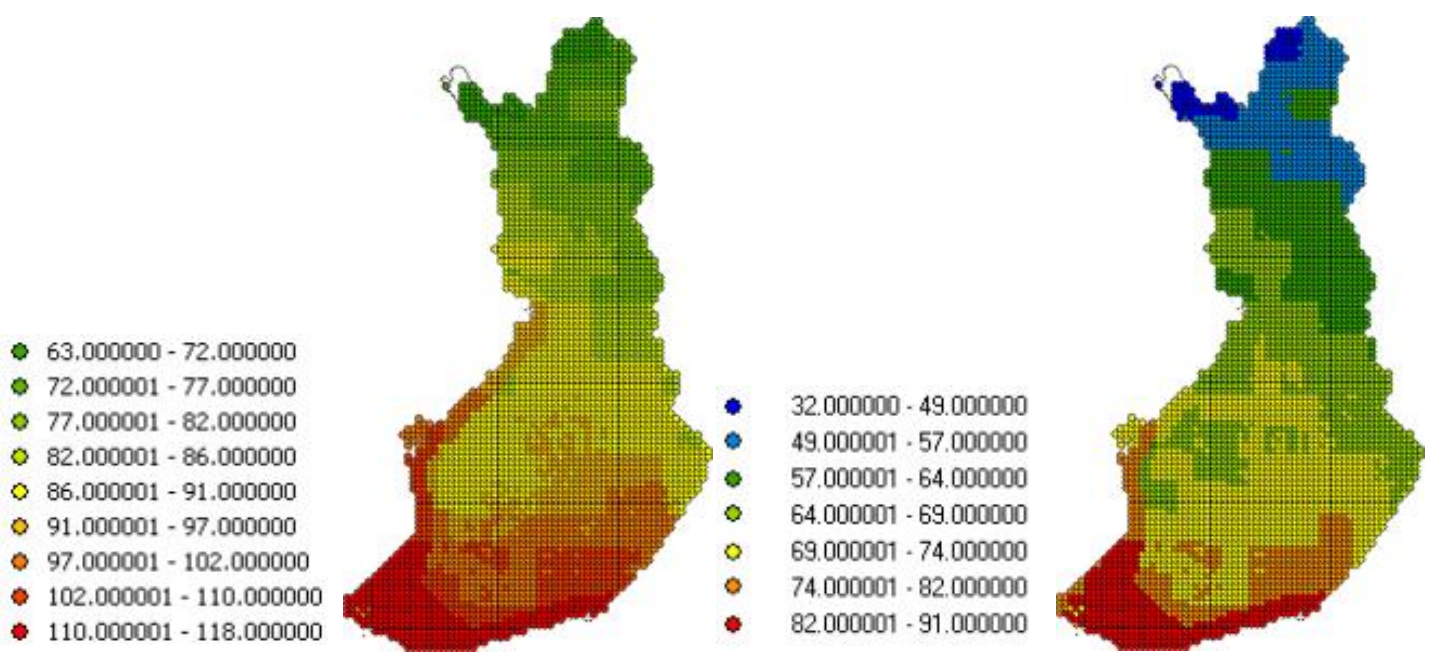

Kuva 1. Vasen (1a): Koloradonkuoriaisen aktiivivaiheen keskimääräinen pituus vrk:na skenaario 2085 A2 mukaan. Oikea (1 b): Aktiiviselle levinnälle suotuisten päivien lukumäärä skenaario 2085 A2 mukaan. 


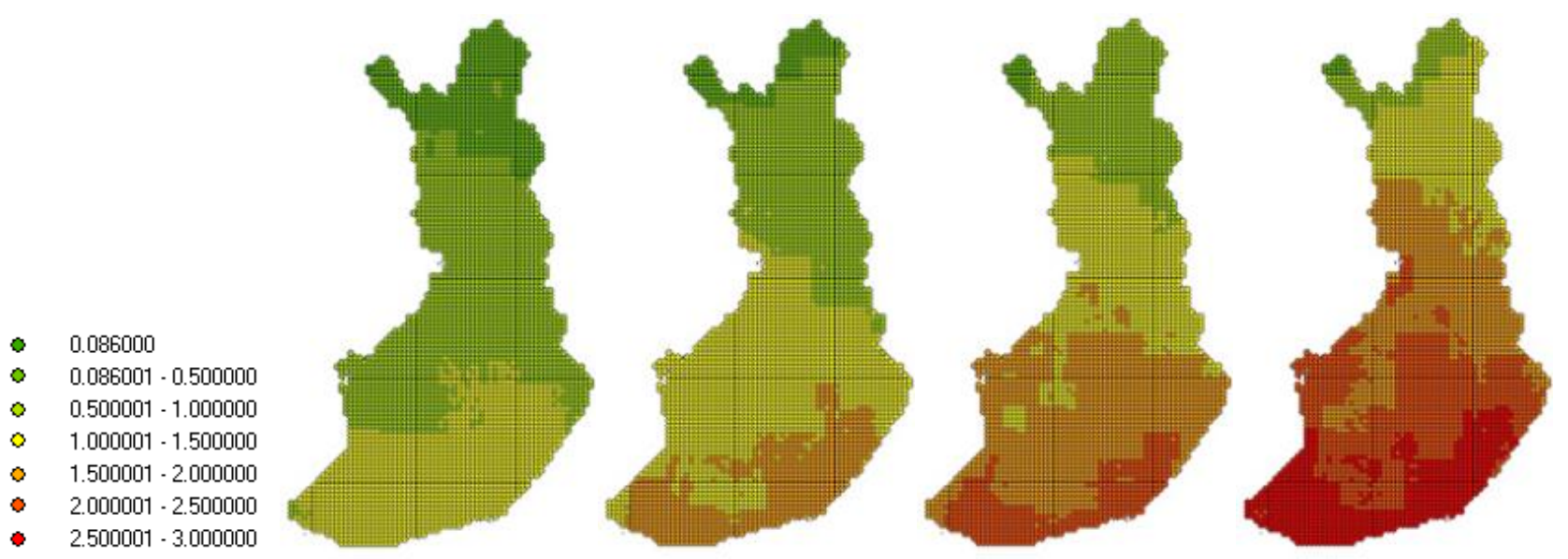

Kuva 2. Koloradonkuoriaisen sukupolvien määrät: I v.1971-2000, II 2025 A2, III 2055 A2, IV 2085 A2. Sukupolvien määrä kasvaa tällä vuosisadalla siten, että kuoriaisia voi esiintyä aina Etelä- ja Keski-Suomesta Lappiin asti. Vuosisadan loppupuolella vain käsivarren Lappi ja maan pohjoisimmat osat ovat keskiarvoisesti niin kylmiä, ettei koloradonkuoriainen ehdi tuottaa yhtään sukupolvea.

Kesien lämpeneminen tuo koloradonkuoriaiselle myös lisää päiviä, jolloin lentoonlähdön lämpökynnys täyttyy (Kuva 1b). Yksi merkittävistä alueista on Kaakkois-Suomi, jossa lentoonlähtöpäiviä on n.74-82 ja kun lisäksi sukupolvia voilla olla 2-3, niin alueella talvehtineilla ja Venäjän Karjalasta mahdollisesti tulleilla kuoriaisilla on hyvät levintäresurssit. Torjunnan kannalta alueella on huomattava levintäriski. Kun lisäksi on ennustettu, että kesällä kuumat päivät yleistyvät ja hellejaksot pitenevät, niin lentoonlähdölle äärimmäisen suotuisia päiviä voi esiintyä poikkeusvuosina hyvin runsaasti, jolloin kuoriaset pääsevät levittäytymään lähialueille. Tämän lisäksi levintäriskiä nostavat yleistyvät kesäiset myrskyt, jotka voivat kuljettaa kuoriaisia hetkessä eri puolille maata.

Parhaimmat oltavat koloradonkuoriaiselle v. 2012-2100 näyttävät kesien osalta olevan Etelä- ja Kaakkois-Suomessa, mutta Pohjois-Suomessa uudeksi tarkkailtavaksi alueeksi nousee Rovaniemi-Pello -linja. Mutta alueet, joilla kesät tarjoavat hyvät lisääntymis- ja levintäresurssit, eivät välttämättä ole parhaimpia talvehtimiseen. Kuva 3 esittää, miten talvet lämpenevät Lounais-Suomesta alkaen siten, että lämpimintä jaksolla 2070-2099 arvioidaan olevan talvisin etelä- ja länsirannikolla, Lounais-Suomessa ja Etelä-Pohjanmaalla. Alustavien talvikuolleisuusmallinnuksiemme mukaan talvehtimisen kannalta parhaimpia ovat alueet, joilla ei esiinny kylmäshokkeja etenkään talvehtimisen alku- ja loppuvaiheessa, eikä myöskään ääreviä suojasääkausia, jotka päättyvät erityisen kylmiin pakkasperiodeihin.

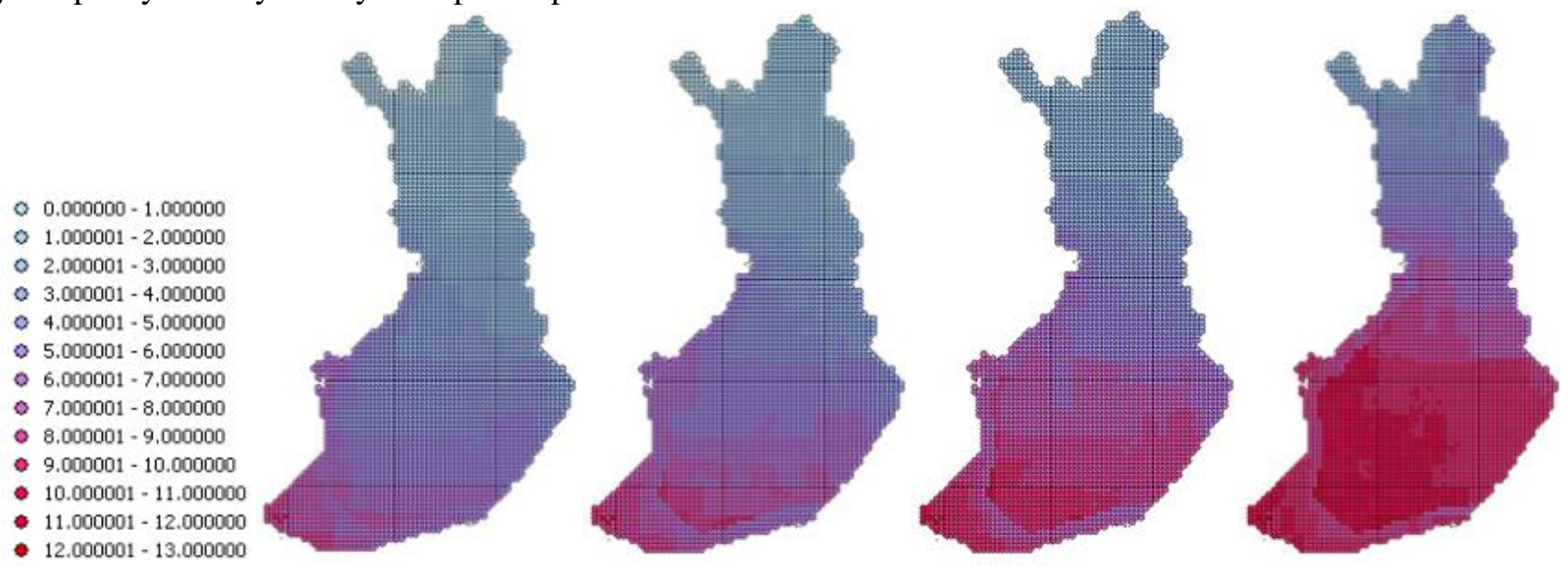

Kuva 3. Suojasääsummaan perustuvan indeksin arvot kohoavat vuosisadan loppua kohti mentäessä. Muutos alkaa etelärannikolta ja on voimakkainta Etelä ja Länsi-Suomessa. Kartat: : I v.1971-2000, II 2025 A2, III 2055 A2, IV 2085 A2. 
Tällaisia ovat ne alueet, joilla talvet ovat joko tasaisen lämpimiä, mutta eivät liian sateisia ja toisaalta alueet, joilla talvet ovat tasaisen kylmiä, joilla on pysyvä lumipeite ja joilla kylmäshokit ovat harvinaisia. Ilmastonmuutoksen myötä tällainen tasaisen leuto alue näyttäisi muodostuvan alueelle, jossa lähimenneisyydessä vielä oli useita suojasääkausia, mutta jossa tulevaisuudessa suojasääkaudet sulautuvat yhdeksi yhteneväksi suojasäätalveksi. Tällainen leudon talven alue (Kuva 4: tumman sininen) näyttäisi syntyvän etelä- ja länsirannikolle, LounaisSuomeen ja Pohjanmaalle aina Ouluun asti ulottuvalle vyöhykkeelle. Muualla Suomessa selkeiden pakkasperiodien toisistaan erottamat suojasääkaudet jatkavat yleistymistään, mikä lisää talvikuolleisuutta. Talvisateiden lisääntyminen, lämpenevät talvet sekä lumipeitteen oheneminen tai totaalinen puuttuminen (Jylhä em. 2004,2008) tulevat siis todennäköisesti vähentämään koloradonkuoriaisen talvehtimisresursseja kaikkialla muualla paitsi em. leudon talven vyöhykkeellä ja Keski-Lapissa, jossa voidaan olettaa säilyvän lumipetteisyyden, koska suojasääkausien määrä pysyy maltillisena. Talvehtimisen kannalta parhaat resurssit koloradonkuoriaiselle ovat leudon talven vyöhykkeellä kunhan runsailta sateilta ja niiden aiheuttamalta märkästressiltä vältytään ja lisäksi Etelä- ja KeskiLapissa, jos seuraava kevät tulee riittävän pian, eli niin, ettei talvehtimiseen käytettävät vararavinnot ehdi ehtyä talven pituuden vuoksi.

Tulostemme mukaan kotiutumaan pyrkivät koloradonkuoriaiset tulevat kohtaamaan eri haasteet etelässä kuin pohjoisessa. Parhaimmat oltavat ovat etelässä sellaisina vuosina jolloin talvi on tasainen, kun taas pohjoisessa mikäli sattuu hyvin lämmin kesä, sitä seuraava tasainen talvi ja riittävän aikainen kevät. Näyttäisi siis siltä, että Etelä-Suomessa kesän suotuisuuden kasvua leikkaa osittain talvien vastaava epäsuotuisuus. Pohjoisessa tulee vastaan kesän lyhyys ja viileys, mutta talvet muuttuvat suotuisimmiksi, kun ne lyhenevät ja kylmäshokkien määrä pienenee eikä ääreviä suojasäitä esiinny niin yleisesti kuin etelässä.

\section{Johtopäätökset}

Aikaisemmin koloradonkuoriaisen kohdalla on kartoitettu kotiutumisriskiä ajanjakson 1961-1990 sääaineistolla vuonna 1994, kun virallista suojavyöhykestatusta haettaessa tehtiin tieteellinen PRA (Pest Risk Assessment). Tässä tutkimuksessa on käytetty kuitenkin laajempaa kirjoa indeksejä kun PRA selvityksissä yleisesti käytetyssä CLIMEX-ohjemistossa (ks. Sutherst ym. 2007). Suomessa ei ole aikaisemmin kartoitettu alueellisia eroja näin tarkalla resoluutiolla periodille 1971-2000 eikä eri skenaarioille. Itse resurssi-indeksien kohdalla uutta ovat levintää ja talvehtimista kuvaavien tunnuslukujen mallinnus ja käyttöönotto.

Monet tutkijat ovat luoneet omia resurssi- ja riski-indeksejä ja näitä on myös koloradonkuoriaisen kohdalla (ks. Jarvis \& Baker ym. $2001 \mathrm{a}, \mathrm{b}$ ), mutta talvehtimisen aikaisten resurssien kuvaaminen on yhä suuri haaste. Parhaimmatkaan meteorologiset indeksit (esim. Jylhä ym. 2004, 2008 ja Laapas 2008) eivät pysty korvaamaan sitä tosiasiaa, että on löydettävä yhteys sääilmiöiden ja hyönteisen fysiologian välille. Tämä käy selkeästi ilmi alustavista tutkimuksistamme, joiden perusteella talven kylmäshokit ja suojasääkausien ankaruus selittävät talvikuolleisuutta paremmin kuin suoja- ja pakkassummiin perustuvat indeksit, vaikka mukaan otettaisiin yleistä lämpötilan vaihtelua nollan molemmin puolin kuvaava $0^{\circ}$-indeksi. Talvien merkitys riskiarvioinneissa näyttää korostuvan entisestään, mistä syystä jatkotutkimuksissa tulisi keskittyä nimenomaan tulokaslajien talvehtimistutkimuksiin. Se miten talvehtiminen onnistuu, nousee selkeästi kynnyskysymykseksi, eikä niinkään kesien sääolot. 
Näitä resurssituloksia voidaan käyttää osana koloradonkuoriaisen seurantaan ja torjuntaan liittyvässä päätöksenteossa. Kesällä torjuntaa voidaan kohdentaa esim. levintäresurssien perusteella ja talven jälkeisessä seurannassa voidaan puolestaan tarkailla erityisesti alueita, joilla talvehtimisresurssit ovat olleet hyvät. Yleisesti ottaen torjuntapäätöksistä tekee haastellisen jatkossa juuri se, että käsiteltäviä kohteita voi olla niin paljon, että on päätettävä, missä järjestyksessä torjuntaa olisi tehokkainta tehdä. Käytännön siirrytään monikriteeriseen päätöksentekoon eli arvottamiseen ja torjuntakohteiden priorisointiin, jossa yhtenä tekijänä ovat juuri sääolot. Toki on muistettava, että tulokastuholaisen levintään vaikuttavat muutkin tekijät kuin yksin ilmastolliset resurssit. Levintä tapahtuu aina kuoriaisen habitaattiverkostossa ja siihen liittyy perunapeltoverkoston kytkeytyvyystekijöiden lisäksi myös passiivisen kulkeutumisen problematiikka, oli sitten kyse myrskyistä tai ihmisten välityksellä siirtymisestä. Lisäksi on hyvä muistaa, että skenaarioilla ei päästä käsiksi yksittäisten talvien ja kesien ääri-ilmiöihin, joihin viranomaisten on joka tapauksessa varauduttava omalla strategiallaan.

Jotta voimme onnistua seuranta- ja torjuntatyössä, on äärimmäisen tärkeää, että tutkijat työskentevät yhdessä päättäjien ja hallintosektorin toimijoiden kanssa. Vain näin voimme kehittää hallinnonalan tarvitsemia uusia toimintoja. Jokainen tieteellistä pohjaa lisäävä tutkimus on edistysaskel kohti käytännössä toimivaa, operatiivista päätöksenteon työkalua joka voisi olla esim. paikkatietopohjainen (Spatial Decision Support System).

\section{Kirjallisuus}

EVIRA. 2011. Jäikö koloradonkuoriainen talvehtimaan? Julkaistu 5.10.2011. Viitattu 9.12.2011. http://www.evira.fi/portal/fi/kasvit/ ajankohtaista /?bid=2745

Hiiesaar, K., Metspalu, J., Jõudu J.\& Jõgar K. 2006. Over-wintering of the Colorado potato beetle (Leptinotarsa decemlineata Say) in the field conditions and factors affecting its population density in Estonia.

Jarvis, C. \& Baker, R. 2001a. Risk assessment for nonindigenous pests: 1. Mapping the outputs of phenology models to assess the likelihood of establishment. Diversity and Distributions 7: 223-235.

Jarvis, C. \& Baker, R. 2001b. Risk assessment for nonindigenous pests: 2. Accounting for interyear climatic variability. Diversity and Distributions 7: 237-248.

Jylhä, K., Tuomenvirta, H. \& Ruosteenoja, K. 2004. Climate change projections for Finland during the 21 st century. Boreal Environment Research 9: 127-152.

Jylhä, K., Fronzek, S., Tuomenvirta, H., Carter, T.R. \& Ruosteenoja, K. 2008. Changes in frost, snow and Baltic Sea ice by the end of the twenty-first century based on climate model projections for Europe. Climatic Change 86: 441-462.

Laapas, M. 2008. Puutarhakasvien talvehtiminen manner-Suomen ilmastossa - nyt ja tulevaisuudessa. Pro gradu-tutkielma: meteorologia. Helsingin yliopisto. Fysikaalisten tieteiden laitos. $62 \mathrm{~s}$.

Ooperi, S. \& Jolma, A. 2009. Modeling invasion dynamics of Colorado beetle to test spatially targeted management strategy. In Anderssen, R.S., R.D. Braddock and L.T.H. Newham (eds) 18th World IMACS Congress and MODSIM09 International Congress on Modelling and Simulation. Modelling and Simulation Society of Australia and New Zealand and International Association for Mathematics and Computers in Simulation, July 2009, pp.1957-1963 . ISBN: 978-0-97584007-8.http://www.mssanz.org.au/modsim09/F4/ooperi.pdf

Peltonen-Sainio, P., Hakala, K., Jauhiainen, L. \& Ruosteenoja, K. 2009. Comparing regional risks in producing turnip rape and oilseed rape - Impacts of climate change and breeding. Acta Agriculturae Scandinavica, B Plant and Soil Science 59: 129-138.

SPSS Inc. 2007. SPSS Classification Trees 16.0. Chicago. Printed in the United States of America. $108 \mathrm{s.}$

Sutherst, R., Maywald, G. \& Kriticos, D. 2007. CLIMEX v. 3 User's Guide. CSIRO \& Hearne Scientific Software Pty Ltd. Melbourne, Australia. $131 \mathrm{~s}$. 